José Marçal Jackson Filho ${ }^{\text {a }}$

Eduardo Garcia Garcia ${ }^{\text {b }}$

Cézar Akiyoshi Saito ${ }^{b}$

a Editor chefe da RBSO

${ }^{\mathrm{b}}$ Editor executivo da RBSO

Contato:

José Marçal Jackson Filho

E-mail:

jose.jackson@fundacentro.gov.br

\section{Sobre o projeto da Fundacentro para as próximas décadas}

\author{
About Fundacentro plan for the next decades
}

\section{A natureza e as tensões atuais do campo da Saúde do Trabalhador}

A Saúde do Trabalhador (ST) é um campo que convoca, acima de tudo, a ação pública. Os acidentes de trabalho geram custos elevados ao Estado brasileiro e grande ônus para trabalhadores, famílias, empresas e para a sociedade de modo geral.

As experiências e políticas mais efetivas para a prevenção de acidentes ocorreram na Escandinávia, quando os países que a compõe possuíam políticas públicas com forte participação do Estado ${ }^{1}$.

No entanto, a tensão entre ação do Estado e transferência das ações para o controle interno das empresas move o campo ${ }^{1}$. No caso brasileiro, essa tensão sempre pendeu para o controle interno das empresas, reforçada pela diminuição progressiva de agentes públicos de inspeção do trabalho e baixo orçamento para as instituições públicas. Mas, contraditoriamente, as consequências da falta de prevenção são transferidas ao Estado ou tornam-se objeto de processos judiciais.

A recente catástrofe envolvendo a mineradora Samarco ${ }^{2}$ ilustra a insuficiência da política nacional de prevenção de acidentes, além da fragilidade das instituições públicas que devem regular e fiscalizar o setor produtivo.

No que tange às instituições de pesquisa do campo da ST, a cobertura da mídia mostrou sua ausência e exclusão do processo de investigação e compreensão do que ocasionou o acidente em Mariana. Mas, o caso da Samarco não é único: de modo geral, as instituições públicas de pesquisa não são chamadas a contribuir para desvelar as causas das tragédias recentes, a ajudar a sociedade a aprender com elas e a subsidiar o Estado a criar mecanismos para impedi-las. Tampouco são chamadas para discutir questões com importantes implicações para a ST, como o debate sobre a terceirização.

A grande contradição é que a pesquisa, a produção de conhecimentos, é fundamental para a produção dos serviços e para a ação do Estado no campo. Entender os determinantes e as causas dos agravos à saúde no trabalho, desenvolver metodologias de intervenção, contribuir com o processo normativo, desenvolver tecnologias e sistemas para a prevenção resultam da produção científica e acadêmica pública e, em menor escala, privada.

A qualidade e impacto da produção científica dependem não apenas da capacidade das instituições em absorver a demanda social e tratar dos 
problemas existentes (valendo-se dos recursos e meios disponíveis), mas, sobretudo, da possibilidade de defender uma posição independente quando convocadas para o debate social.

\section{Sobre os 50 anos da Fundacentro}

A Fundacentro teve papel central nas primeiras políticas de prevenção do Brasil no início dos anos 1970. Sua maior contribuição nesse período foi a formação da comunidade profissional, composta por médicos e enfermeiros do trabalho, engenheiros e técnicos de segurança, além da construção inicial do marco legal existente.

No entanto, até meados dos anos 1980, também teve atuação influenciada pela ideologia então dominante do ato inseguro, que contribuiu com um legado extremamente negativo e que compromete até hoje a segurança e a saúde dos trabalhadores. No final dos anos 1980 a instituição passou a rever tais fundamentos e a contribuir com importantes ações preventivas contra diversos problemas, como foi o caso da exposição ao benzeno e ao amianto, do trabalho em galvânicas, entre outros, além de participar da elaboração de novas normas regulamentadoras com enfoque mais abrangente para a prevenção.

Não obstante, as mudanças no mundo do trabalho colocaram a Fundacentro em situação paradoxal, uma vez que não houve concursos suficientes para recompor seus quadros ao longo dos últimos 28 anos e requalificar sua atuação. Como esse quadro é composto majoritariamente por técnicos que atuam na prevenção de riscos tradicionais do trabalho (riscos ambientais), a instituição está menos preparada, diante da falta de especialistas nas áreas sociais, para tratar das questões mais recentes trazidas pela reestruturação produtiva que envolvem problemas musculoesqueléticos ou de saúde mental, entre outros ${ }^{3}$.

Por outro lado, a instituição perdeu, a partir de meados dos anos 1980, a centralidade que possuía na condução da política de prevenção ${ }^{4}$. Além disso, diante das mudanças frequentes dos cargos de direção aliadas às insuficiências organizacionais, da redução de recursos orçamentários ao longo do tempo e da diminuição de quadros de servidores ativos, a Fundacentro diminuiu sua capacidade de intervir e de defender uma posição autônoma, baseada em conhecimentos científicos solidificados, nos debates fundamentais do campo da saúde e do trabalho, como no recente projeto de lei sobre a terceirização ou no caso da catástrofe da Samarco.

\section{O projeto para os próximos anos}

O projeto de atuação da Fundacentro deve estar atrelado a um movimento que coloque a ST no centro da agenda política. Pensar na ST é pensar o modelo de desenvolvimento e de atuação do Estado, em novas relações sociais. É preciso recolocar a instituição num papel central na política de Estado para o campo, mas de forma articulada com outras instituições, como a Fiocruz, Ipea, INSS, Ministério Público, universidades, entre outras.

É preciso recompor e redesenhar, por meio de concursos públicos, as vagas do seu corpo técnico e administrativo tendo em mente a demanda social atual, a fim de capacitar a instituição a intervir de forma mais consistente, também, no campo das ciências sociais e econômicas e do direito. É necessário, em especial, que se crie um grupo especializado na análise e prevenção de acidentes e catástrofes que sirva de referência para o Estado brasileiro, atuando em parceria com universidades e outras organizações (Fórum de Acidentes do Trabalho ${ }^{5}$, por exemplo). Essa é uma medida urgente a ser considerada diante da inexistência, no país, de dispositivo semelhante.

A legitimidade a ser conquistada pela instituição depende ainda de maior inserção no sistema de ciência e tecnologia nacional, maior aproximação com órgãos de fomento à pesquisa, cooperação com instituições de outros países (inclusive da América Latina) e também do fortalecimento de cultura interna voltada à pesquisa.

Recentes desenvolvimentos, como a criação do mestrado acadêmico "Trabalho, saúde e ambiente" e a reestruturação da Revista Brasileira de Saúde Ocupacional, mostram que, a despeito de suas limitações, a Fundacentro reúne condições para contribuir em colocar a ST na agenda pública e política do Brasil de hoje e das próximas décadas. 


\section{Referências}

1. Vogel L. Prevention at the workplace. The impact of community directives on preventive systems in Sweden, Finland, Norway, Austria and Switzerland. Brusells: European Trade Union Technical Bureau for Health and Safety; 1998.

2. Porto MFS. A tragédia da mineração e do desenvolvimento no Brasil: desafios para a saúde coletiva. Cad Saúde Pública [Internet]. 2016 [citado 2016set 1];32(2):e00211015. Disponível em: http://www.scielo.br/scielo. php?script $=$ sci_arttext\&pid $=$ S0102-311X2016000200302\&lng $=$ pt

3. Teixeira EM. Atuação da Fundacentro: avaliação institucional e fatores explicativos no contexto da ciência e tecnologia [dissertação]. Rio de Janeiro: Universidade Federal do Rio de Janeiro; 2011.

4. Jackson Filho JM, Algranti E, Saito CA, Garcia EG. Da segurança e medicina do trabalho à Saúde do Trabalhador: história e desafios da Revista Brasileira de Saúde Ocupacional. Ciênc saúde coletiva [Internet]. 2015jul [citado 2016set1];20(7):2041-2051. Disponível em: http:/www.scielo.br/scielo.php?script=sci_ arttext\&pid $=$ S1413-81232015000702041\&lng $=$ pt

5. Jackson Filho JM, Vilela RAG, Garcia EG, Almeida IM. Sobre a "aceitabilidade social” dos acidentes do trabalho e o inaceitável conceito de ato inseguro. Rev. bras saúde ocup [Internet]. 2013jun [citado 2016set1];38(127):6-8. Disponível em: http://www.scielo.br/scielo.php?script=sci_arttext\&pid=S0303-76572013000100001\&lng=pt 